\title{
Recurrent pregnancy loss: challenge to obstetricians
}

\author{
Mamatha B. Shetty*, Mounica Malyala, Asha Swarup, Suneha Pocha, \\ Davis Sabu Pathadan, Ankush Raju
}

Department of Obstetrics and Gynecology, Ramaiah Medical College, Bangalore, Karnataka, India

Received: 08 June 2017

Revised: 01 July 2017

Accepted: 14 July 2017

\section{*Correspondence:}

Dr. Mamatha B. Shetty,

E-mail: drmamathabshetty@gmail.com

Copyright: (C) the author(s), publisher and licensee Medip Academy. This is an open-access article distributed under the terms of the Creative Commons Attribution Non-Commercial License, which permits unrestricted non-commercial use, distribution, and reproduction in any medium, provided the original work is properly cited.

\section{ABSTRACT}

Background: Recurrent pregnancies loss (RPL) is physically and emotionally devastating situation for the parents, along with difficult situation for obstetrician to handle. Present study aimed at investigation of the significance of various etiology in relation to pregnancy outcome in cases of recurrent pregnancy loss.

Methods: It is a retrospective analysis of patients who presented to M. S. Ramaiah Medical college with recurrent miscarriage between April 2014 and August 2015. ANA was done on the basis of clinical and laboratory data which was obtained and eventually diagnosis was made. The study results were analysed in terms of term live births, maternal and fetal complications.

Results: Out of the RPL cases that were studied, 78 patients came with recurrent pregnancy loss. Out of these cases, endocrine abnormalities, like diabetes mellitus and hypothyroidism were the maximum $26.92 \%$ and $12.82 \%$ respectively. Followed by unexplained causes were 37.3\%. Thrombophila and APLA positive cases constituted for $16.66 \%$ and $3.4 \%$ respectively. ANA positive and cervical incompetence were $6.4 \%$ each.

Conclusions: Recurrent pregnancy loss is very difficult situation to handle. Various etiology need various specialists, and requirements, and management mainly depends on the cause for recurrent pregnancy loss.

Keywords: High risk, Pregnancy, Recurrent

\section{INTRODUCTION}

Recurrent pregnancies loss (RPL) is physically and emotionally devastating situation for the parents, along with difficult situation for obstetrician to handle. Recurrent pregnancy loss is three or more clinically recognized consecutive, spontaneous losses under 20 weeks. ${ }^{1}$ Approximately $5 \%$ of women will experience two consecutive miscarriages, and only $1 \%$ experience three or more miscarriages. ${ }^{2}$

Identification of RPL is truly a challenging problem due to the increasing number of sporadic miscarriages. Sporadic loss generally due chromosomal abnormalities, and present before 10 weeks of gestation. ${ }^{3}$ Recurrent pregnancy loss is classified into to two types, primary RPL, which consists of repeated miscarriages in which pregnancy has never been carried to viability, and secondary RPL in which live birth has occurred at some time.

Many significant factors play a role in RPL, from maternal factors such as age, uterine anomalies, hormonal and/or metabolic disorders, to various syndromes like antiphosolipid syndrome, sperm quality, infections, lifestyle. Although many factors play a role, the proven etiology are few: parental chromosomal abnormalities, untreated hypothyroidism, uncontrolled diabetes mellitus, uterine abnormalities, and antiphospholipid antibody syndrome (APS). 
The objectives are to identify various cause and factors that play a role in the recurrent pregnancy loss, the amount of studies and research done in the aspect are less, and continuous research will allow us to better understand and evaluate the patient better.

\section{METHODS}

Retrospective cohorts study, conducted in M.S Ramaiah Medical College and Hospital, Bangalore, from May 2014 to April 2015. The medical records and details were obtained from the MRD, from which data was collected, regarding age, previous history of abortions, comorbidities, any medications, and investigations done. The data collected included all patients, from the above period that gave history of more than 3 abortions. Approval for the study was taken from the Institutional Ethics Committee. The total number cases studied during this one year are 78 of which 66 cases were secondary and 12 primary RPL.

Various blood parameters were taken into consideration, such as ANA, ACLA, LA, HbA1C, serum TSH, B2 glycoprotein, and other basic ANC investigation.

Frequency, percentage, univariate analysis, were used for analytic inference. Analysis was done using SPSS Statistical Software package.

\section{RESULTS}

The total number of cases of recurrent pregnancy loss in our hospital were 78 patients, of which out of which 63 cases $(80.76 \%)$ referred, and 15 cases were booked cases. Among the studied 12 cases were primary RPL, and 66 were secondary. Table 1 and 2 shows various factors that influence recurrent pregnancy loss.

Table 1: Maternal factors.

\begin{tabular}{|lll|}
\hline \multicolumn{1}{|c|}{ No. of case } & $\%$ \\
\hline $21-30$ & & \\
\hline $31-40$ & 42 & 53.84 \\
\hline$>41$ & 34 & 43.58 \\
\hline Number of Abortion & 2 & 2.56 \\
\hline $3-4$ & 42 & \\
\hline$>5$ & 36 & 53.84 \\
\hline Type of RPL & & 46.15 \\
\hline Primary & 12 & \\
\hline Secondary & 66 & 15.38 \\
\hline
\end{tabular}

Epidemiological factor, that come into play such as maternal age is taken into consideration, maternal age is directly proportional to the chromosomal abnormalities, in our study, approximately 42 patients $(53.84 \%)$ are between the age $21-30$, and 34 patients (43.58\%) were 31-40 years. As we further look into data, approximately half $(53.84 \%)$ the patients had 3-4 abortion whereas $46.15 \%$ had more 5 abortions.

Table 2: Etiology of RPL.

\begin{tabular}{|lll|}
\hline Factors & No. of cases & $\%$ \\
\hline Thrombophila & 13 & 16.66 \\
\hline APLA & 3 & 3.84 \\
\hline Protein C & 1 & 1.28 \\
\hline Protein A & 2 & 2.56 \\
\hline ANA & 5 & 6.41 \\
\hline Homocysteine & 1 & 1.28 \\
\hline Cervical incompetence & 5 & 6.4 \\
\hline Endocrine & 31 & 39.74 \\
\hline Abnormalities & & \\
\hline Diabetes mellitus & 21 & 26.92 \\
\hline Hypothyroidism & 10 & 12.82 \\
\hline Unknown & 29 & 37.3 \\
\hline Abnormal karyotyping & 1 & 1.28 \\
\hline
\end{tabular}

Among the etiological factors, endocrine abnormalities played a major role (39.74\%), of which especially diabetes mellitus $(26.92 \%)$ was a leading cause and hypothyroidism was $12.82 \%$.

Table 3: Antenatal treatment.

\begin{tabular}{|lll|}
\hline Medication & No. of patients received & $\%$ \\
\hline Ecosporin & 45 & 57.69 \\
\hline $\begin{array}{l}\text { Low molecular } \\
\text { weight heparin }\end{array}$ & 32 & 41.02 \\
\hline Steroids & 37 & 47.43 \\
\hline Circlage & 5 & 6.41 \\
\hline
\end{tabular}

Thrombophilia is the $3^{\text {rd }}$ most common etiology for recurrent pregnancy loss, and its management is based on giving to ecosporin and low molecular weight heparin and which 45 patients $(57.69 \%)$ received ecosporin and 32 patients $(41.02 \%)$ received low molecular weight heparin. Cervical incompetence is the 4th most common and approximately 5 patients came with findings regarding it. All of the patients with cervical incompetence underwent cervical circlage.

Table 4: Pregnancy outcome.

\begin{tabular}{|lll|}
\hline Outcome & No. of neonates & $\%$ \\
\hline Term & 31 & 39.74 \\
\hline Preterm & 27 & 34.61 \\
\hline IUFD & 02 & 2.56 \\
\hline Pre-eclampsia & 18 & 23.07 \\
\hline
\end{tabular}

Fetal outcome is shown in Table 4. Term delivery was $39.74 \%$ and preterm was $34.61 \%$. Of the 78 cases, 18 patients $(23.07 \%)$ developed pre-eclampsia. And total 2 intrauterine fetal death $(2.56 \%)$. Number of neonates admitted to neonatal intensive care center were 10 neonates of which 4 dead due to various cause such as respiratory distress syndrome, septicemia, and others. 


\section{DISCUSSION}

\section{Epidemiological factors}

Epidemiological factors play have questionable role in RPL, obesity is associated with increased risk of RPL, in women who try to conceive naturally. ${ }^{4}$ Consumption of caffeine, alcohol, and cocaine abuse has been related with miscarriage. ${ }^{5}$ Maternal age is directly affects the chromosomal abnormalities.

\section{Uterine anomalies}

Uterine anomalies, such as unicoruate, didelphic, bicornuate, septate, or arcuate uteri, are present in approximately $12.6 \%$ if the case with recurrent pregnancy loss. ${ }^{6}$ Correction of these anatomical defects may improve the chance in recurrent pregnancy loss, but due to the lack of study, it is controversial. Cervical incompetence is another major anatomical anomaly that is associated with RPL. Acquired disease such as Asherman syndrome, uterine fibroids, and polyps also play a role in RPL, but its definitive role is inconclusive. According to the current study, 5 patients $(6.41 \%)$ presented with cervical incompetence. Effective methods in identification of uterine anomalies is based on transvaginal ultrasound and hysteroscopy. There is no satisfactory test or investigations for identification of cervical incompetence, and diagnosis is made mostly on basis of history.

\section{Parental chromosomal abnormalities}

Parental chromosomal abnormalities are detected in about $2-8 \%$ of couples with recurrent pregnancy loss among which balanced translocations are the most frequent abnormalities. ${ }^{7,8} \quad$ Unbalanced structural genetic rearrangement is present $36-39 \%$ of the couples with recurrent pregnancy loss. ${ }^{9,10}$ Peripheral blood karyotyping, cytogentic analysis of products on conception are ways to rule out chromosomal abnormalities. Management of these couples is a difficult task, and mostly based on genetic conuselling can provide the couple with a prognosis for future pregnancy.

\section{Hormonal abnormalities}

Hormonal abnormalities are the easiest to identify recurrent miscarriages, many hormones have an important function in the development and growth of the fetus. Endocrine disorders play a major role in approximately $8 \%$ to $12 \%$ of recurrent pregnancy loss (RPL). ${ }^{11}$ Endocrine abnormalities, including thyroid disorders, luteal phase defects, polycystic ovary syndrome, hyperprolactinaemia and diabetes have to be evaluated in any case of RPL.

\section{Thyroid abnormalities}

Thyroid disorders both hyperthyroidism and hypothyroidism have an effect on pregnancy.
Hyperthyroidism is present in about $0.1-0.4 \%$ of pregnancies and excessive hormone leads to increased risk of spontaneous miscarriage. ${ }^{12-13}$ Whereas untreated hypothyroidism in pregnancy has soon adverse effects on pregnancy from increased miscarriages to fetal neurocognitive development. ${ }^{14}$

\section{Diabetes mellitus}

Type 1 and 2 Diabetes mellitus both have deleterious affects on pregnancy, but pregestational glucose levels, have important role in pregnancy. High levels of glucose have tetratogenic, leading to congenital fetal anomalies. Strict monitoring of sugars during preconceptional period reduces the risk of RPL. ${ }^{15,16}$

\section{Hyperprolactinemia}

Elevated prolactin levels are associated with ovulatory dysfunction, high levels PRL levels inhibit progesterone secretion resulting in luteal phase defects. Patients with RPL associated with hyperprolactinaemia treated with bromocriptine have higher incidence of successful pregnancy. ${ }^{17}$

\section{Polycycstic ovarian disorder}

Heterogenous disorder, characterized by obesity, hyperinsulinaemia, insulin resistance, hyperhomocystenaemia, hyperandrogen, and poor endometrial re-activity. Recent studies show that presence of hypofibronolysis associated with PAI-1 is potential cause for RPL in women with PCOS. ${ }^{18}$ Many mechanisms of PCOD may play contribute individually or together in leading to RPL. Metoformin treatment in patients with PCOS, improves ovulation cycles and decreases the risk of RPL. ${ }^{19}$

\section{Antiphospholipid syndrome}

Antiphospholipid syndrome is an autoimmune disorder that is associated with pregnancy complications, characterized by antiphospholipid antibodies interacting with phospholipid binding proteins in the body, most important one being beta 2-glycoprotein. These antibodies inhibit villow cytotrophoblast differentiationm and extravillious cytotrophoblast invasion into decidua, induction of syncytiotrophoblast apoptosis, and initiation of maternal inflammatory reaction.

Approximately 8 to $42 \%$ of the patients with recurrent pregnancy loss are positive for antiphospholipid antibodies. $^{20}$ The most widely accepted tests are lupus anticoagulant, anticardiolipin antibody, and antibeta gylcoprotein 1. The diagnostic criteria are mentioned in Table 5. ${ }^{20}$ Treatment for antiphospholipid syndrome consists of low dose of aspirin and heparin which leads to $74.3 \%$ live born rate. ${ }^{21}$ 
Table 5: International consensus classification criteria for antiphospholipid syndrome.

International consensus classification criteria for antiphospholipid syndrome

APS is present if one of the following clinical criteria and one of the laboratory criteria are met

Clinical criteria

Vascular thrombosis

Pregnancy criteria

One or more unexlpained deaths of morphologically normal fetuses after 10th week of gestation by ultrasound or direct examination of the fetus

One or more premature births of a morphologically normal neonate before the 34th week of gestation because of eclampsia or severe pre-eclampsia or recognized features of placental insufficiency

Three or more unexplained consecutive spontaneous abortions before 10th week of gestation with maternal anatomic or hormonal abnormalities and paternal and maternal chromosomal causes excluded

\section{Laboratory criteria}

Lupus anticoagulant present in plasma on two or more occasions at least 12 weeks apart or, Anticardiolipin antibody of IgG or IgM isotype in serum or plasma present in medium or high titer ( $>40 \mathrm{GPL}$ or MPL or $>99^{\text {th }}$ percentile), on two or more occasions at least 12 weeks apart or, Anti Beta glycoprotein-1 antibody of IgG or IgM isotype in serum or plasma greater than the $99^{\text {th }}$ percentile present two or more occasions at least 12 weeks apart

\section{CONCLUSION}

Recurrent pregnancy loss is both a financially and emotionally tolling effects. Coordination of multiple specialists are required in evaluation and management of patients with RPL. This should include gynecologists, geneticists, rheumatologist, hematologists, immunologists, and reproductive specialist. Data on management of RPL is limited, and treatment is mostly based on underlying cause of RPL. But the most important is tender, love, and care.

\section{Funding: No funding sources}

Conflict of interest: None declared

Ethical approval: The study was approved by the Institutional Ethics Committee

\section{REFERENCES}

1. Stirrat GM. Recurrent miscarriage. Lancet 1990;336:673.

2. Van den Boogaard E, Kaandorp SP, Franssen MT, Mol BW, Leschot NJ et al. Consecutive or nonconsecutive recurrent miscarriage: is there any difference in carrier status? Hum Reprod. 2010;25:1411.

3. Jacobs PA, Hassold T. Chromosome abnormalities: origin and etiology inabortions and livebirths. In: Vogel F, Sperling K, editors. Human genetics. Berlin: Springer-Verlag; 1987:233-44.

4. Boots C, Stephenson MD. Does obesity increase the risk of miscarriage in spontaneous conception: a systematic review. Semin Reprod Med. 2011;29:50713.

5. Ness RB, Grisso JA, Hirshinger N, Markovic N, Shaw LM, Day NL et al. Co-caine and tobacco use and the risk of spontaneous abortion. N Engl J Med. 1999;340:333-9.
6. Grimbizis GF, Camus M, Tarlatzis BC, Bontis JN, Devroey P. Clinical implications of uterine malformations and hysteroscopic treatment results. Hum Reprod Update. 2001;7:161-74.

7. Elghezal H,Hidar S, Mougou S, Khairi H, Saad A. Prevalence of chromosomal abnormalities in couples with recurrent miscarriage. Fertil Steril. 2007;88:721-3.

8. Tharapel AT, Tharapel SA, Bannerman RM. Recurrent pregnancy losses and parental chromosome abnormalities: a review. BJOG: An International J Obstetr Amp Gynaecol. 1985;92:899914.

9. Sugiura-Ogasawara M, Ozaki Y, Sato T, Suzumori $\mathrm{N}$, Suzumori K. Poor prognosis of recurrent aborters with either maternal or paternal reciprocal translocations. Fertil Steril. 2004;81:367-73.

10. Sierra S, Langlois S, Stephenson MD. Reproductive outcomes in patients with recurrent pregnancy loss associated with a structural chromosome abnormality. Fertil Steril. 2003;80:80-1.

11. Smith ML, Schust DJ. Endocrinology and recurrent early pregnancy loss. Semin Reprod Med. 2011;29:482-90.

12. Glinoer D. Thyroid hyperfunction during pregnancy. Thyroid. 1998;8:859-64.

13. Millar LK, Wing DA, Leung AS, Koonings PP, Montoro MN, Mestman JH. Low birth weight and preeclampsia in pregnancies complicated by hyperthyroidism. Obstet Gynecol. 1994;84:946-9.

14. Abalovich M, Gutierrez S, Alcaraz G, Maccallini G, Garcia A, Levalle O. Overt and subclinical hypothyroidism complicating pregnancy. Thyroid. 2002;12:63-8.

15. Rai R, Regan L. Recurrent miscarriage. Lancet. 2006;368:601-11.

16. Nicholson W, Baptiste-Roberts K. Oral hypoglycaemic agents during pregnancy: The 
evidence for effectiveness and safety. Best Pract Res Clin Obstet Gynaecol. 2011;25:51-63.

17. Hirahara F, Andoh N, Sawai K, Hirabuki T, Uemura T, Minaguchi H. Hypecprolacrinemic recurrent miscarriage and results of randomized bromocriptine treatment trials. Fertil Steril. 1998;70:246-252.

18. Sun L, Lv H, Wei W, Zhang D, Guan Y. Angiotensin-converting enzyme D/I and plasminogen activator inhibitor-1 4G/5G gene polymorphisms are associated with increased risk of spontaneous abortions in polycystic ovarian syndrome. J Endocrinol Invest. 2010;33:77-82.

19. Tang T, Lord JM, Norman RJ, Yasmin E, Balen AH. Insulin-sensitising drugs (metformin, rosiglitazone, pioglitazone, D-chiro-inositol) for women with polycystic ovary syndrome, oligo amenorrhoea and subfertility. Cochrane Database Syst Rev. 2012;5:CD003053.

20. American College of Obstetricians and Gynecologists Committee on Practice BulletinsObstetrics. ACOG Practice Bulletin No. 118: antiphospholipid syndrome. Obstet Gynecol. 2011;117(1):192-9.

21. Empson M, Lassere M, Craig JC, Scott JR. Recurrent pregnancy loss with antiphospholipid antibody: a systematic review of therapeutic trials. Obstet Gynecol. 2002;99:135-44.

Cite this article as: Shetty MB, Malyala M, Swarup A, Pocha S, Pathadan DS, Raju A. Recurrent pregnancy loss: challenge to obstetricians. Int J Reprod Contracept Obstet Gynecol 2017;6:3376-80. 